\title{
ANALYSIS OF THE BOUND MODES IN OPTICAL D-FIBERS
}

\section{ANÁLISIS DE LOS MODOS CONECTADOS EN FIBRAS ÓPTICAS TIPO D}

\author{
Antonio R. Sapienza ${ }^{1} \quad$ Marcelo F. Guimarães ${ }^{2}$ \\ Recibido 26 de julio de 2005, aceptado 26 de julio de 2006 \\ Received: July 26, 2005 Accepted: July 26, 2006
}

\begin{abstract}
RESUMEN
En este artículo una solución analítica de un guía de onda con un núcleo circular y del revestimiento ilimitado en la proximidad a un medio espacio dieléctrico se presenta. Este modelo se aplica a la fibra tipo D en proximidad cerrada a un plano. Los resultados explican las características de la birrefringencia de estas estructuras.

Los gráficos de algunos parámetros de la fibra se calculan en función de la frecuencia espacial normalizada.

Palabras clave: Fibra tipo D, formulación híbrida, modos TE y TM, estados de polarización Y y X del modo fundamental, teorema de la dualidad.
\end{abstract}

\section{ABSTRACT}

In this paper an analytical solution of a waveguide with a circular core and unbounded cladding in the proximity to a dielectric halfspace is presented. This model is applied to D-shaped fiber in closed proximity to a plane. The results account for the birefringence properties of these structures.

Graphics of some parameters of the fiber are calculated as a function of the normalized spatial frequency.

Keywords: D-shaped fiber, hybrid formulation, TE and TM modes, polarization-states $Y$ and $X$ of fundamental mode, duality theorem.

\section{INTRODUCTION}

The analytical solution of optical waveguide is generally a very complex problem. There is a great number of known solutions for relatively simple structures such as the circular and elliptical waveguide, and also for some refractive-index profiles, such as step and graded profiles [1]. The analysis of D-shaped fibers is complex. It is described in detail [2] by vector normal modes.

In this paper, we develop a new methodology suitable to analyze the two polarization states of the fundamental modes of the polished-optical fibers, as shown in Fig.1. The birefringence properties of these structures are shown. It is also shown that theses modes approach the properties of TE and TM modes, respectively.

The analysis is done by the hybrid-formulation. The longitudinal components are calculated by Helmhotz equations in generally regions. It is assumed that the permeability and the permittivity of each region are different.

The analysis is developed in two Cartesian coordinate systems: the rectangular and cylindrical polar coordinates. The procedure for connecting the corresponding field expressions in both coordinate systems is the same as used by [2], [3]. The field components, which are expressed in both systems, are matched in the plane interface.

A system of equations in matrix form is obtained in such a way that relates the longitudinal field components. This matrix is called the equivalent scattering-matrix.

This procedure yields a general formulation which is suitable to obtain orthogonal polarization of the fundamental mode.

By considering the relative permeability as one value the formulation provides the TE-mode solution. By

1 Electronics Engineering Department, Universidade do Estado do Rio de Janeiro (UERJ), a_sapienza@osite.com.br

2 Equipment Engineer, PETROBRAS, marcelo.guima@petrobras.com.br 
applying the duality theorem in the general expression and in the equivalent scattering-matrix, the formulation now provides the TM-mode solution.

Thus, the two polarization states of the polishedoptical fiber can be modeled by just using one system formulation.

The theory is verified by plotting the effective-index and the core phase-transversal parameter as function of the normalized-spatial frequency.

The raising of the fiber birefringence was verified by plotting the core phase parameters of both polarization states, at $\mathrm{V}=23$, as function of normalized distance between the core and the plane interface.

\section{MATHEMATICAL MODEL}

An implicit time dependence $\mathrm{e}^{j \omega t}$ is assumed. The waveguide is uniform and only forward wave propagations are considered.

The longitudinal component equations of the electric and magnetic fields are not coupled in regions of constant index. With these assumptions the following pair of equations are obtained:

$$
\begin{aligned}
& {\left[\nabla_{t}^{2}+\left(k^{2} \eta^{2}-\beta^{2}\right)\right] E_{z}=0} \\
& {\left[\nabla_{t}^{2}+\left(k^{2} \eta^{2}-\beta^{2}\right)\right] H_{z}=0}
\end{aligned}
$$

The transversal components are obtained by Hybridformulation [1].

\section{A. Fields in the core and cladding}

In the core, the polarization state-y (TE-modes) consists of superposition of the normal modes expressed by polar coordinate system as follows:

$$
\begin{aligned}
& e_{Z}=\sum_{n=o}^{\infty} A_{n} J_{n}(U R) \operatorname{sen}(n \theta) \\
& h_{Z}=\sum_{n=o}^{\infty} B_{n} J_{n}(U R) \cos (n \theta)
\end{aligned}
$$

In the cladding, the corresponding solutions are given by

$$
\begin{gathered}
e_{Z}=\sum_{n=o}^{\infty}\left[C_{n} K_{n}(W R)+D_{n} I_{n}(W R)\right] \operatorname{sen}(n \theta) \\
h_{Z}=\sum_{n=o}^{\infty}\left[E_{n} K_{n}(U R)+F_{n} I_{n}(U R)\right] \cos (n \theta)
\end{gathered}
$$

where: $A_{n}, B_{n}, C_{n}, D_{n}, E_{n}, F_{n}$ are constants to be determined, $J_{n}, K_{n}, I_{n}$ are Bessel functions of order $n$, $\mathrm{R}$ is the normalized radial coordinate $(\mathrm{R}=\mathrm{r} / \mathrm{a})$, and $\mathrm{U}, \mathrm{W}$ are the normalized modal parameters, which are defined as:

$$
\begin{gathered}
\mathrm{U}=a\left(\mathrm{~K}_{1}^{2}-\beta^{2}\right)^{1 / 2} \\
\mathrm{~W}=a\left(\beta^{2}-\mathrm{K}_{2}^{2}\right)^{1 / 2}=\left(\mathrm{V}^{2}-\mathrm{U}^{2}\right)^{1 / 2}
\end{gathered}
$$

In these equations $\mathrm{V}$ is the normalized spatial frequency. The polarization state-X (TM-modes) is obtained interchanging the sine and cosine functions in (2) and (3).

\section{B. Planar Representation of the Cladding Fields}

As the fields in the halfspace are expanded in terms of continuum plane waves, the representations of the cladding fields by Fourier-Bessel expansion are not appropriate. We used the same approach of [2], [3] to overcome this difficulty.

The cladding fields on the neighborhood of the interface are expanded in rectangular coordinate system by superposition of plane waves:

$$
\begin{aligned}
& e_{Z}=\int_{-\infty}^{\infty}\left[P_{v} e^{-\sigma(X-D)}+Q_{v} e^{\sigma(X+D)}\right] e^{-j Y v} d v \\
& h_{Z}=\int_{-\infty}^{\infty}\left[R_{v} e^{-\sigma(X-D)}+S_{v} e^{\sigma(X+D)}\right] e^{-j Y v} d v
\end{aligned}
$$

where $\mathrm{X}=(\mathrm{x} / \mathrm{a}), \mathrm{Y}=(\mathrm{y} / \mathrm{a})$ are the normalized coordinates. The normalized modal parameter satisfy:

$$
\sigma^{2}=v^{2}+a^{2}\left(\beta^{2}-K_{2}^{2}\right)=\left(v^{2}+\mathrm{W}^{2}\right)
$$

The equivalent terms in (3) and (5) are expressed by two set of equations.

The first set links $\left(\mathrm{Q}_{v}, \mathrm{~S}_{\mathrm{v}}\right)$ to $\left(\mathrm{D}_{\mathrm{n}}, \mathrm{F}_{\mathrm{m}}\right)$

$$
\begin{aligned}
& \sum_{n=o}^{\infty} D_{n} I_{n}(W R) \operatorname{sen}(n \theta)=\int_{-\infty}^{\infty} Q_{v} e^{\sigma(X-D)} e^{-j Y v} d v \\
& \sum_{m=o}^{\infty} F_{m} I_{m}(W R) \cos (m \theta)=\int_{-\infty}^{\infty} S_{v} e^{\sigma(X-D)} e^{-j Y v} d v
\end{aligned}
$$

The second set links $\left(\mathrm{P}_{v}, \mathrm{R}_{v}\right)$ to $\left(\mathrm{C}_{\mathrm{n}}, \mathrm{E}_{\mathrm{m}}\right)$. 


$$
\begin{aligned}
& \sum_{n=o}^{\infty} C_{n} K_{n}(W R) \operatorname{sen}(n \theta)=\int_{-\infty}^{\infty} P_{v} e^{-\sigma(X-D)} e^{-j Y v} d v \\
& \sum_{m=o}^{\infty} E_{m} K_{m}(W R) \cos (m \theta)=\int_{-\infty}^{\infty} R_{v} e^{-\sigma(X-D)} e^{-j Y v} d v
\end{aligned}
$$

It is possible to solve (7) and (8) by appropriate relations of Bessel functions integrals [2]-[3]. The equation coefficients of (7) and (8) are express by:

$$
\begin{aligned}
\varepsilon_{m} F_{m} & =2 \int_{-\infty}^{\infty} S_{v} e^{-\sigma D} \cosh (m g) d v \\
D_{m} & =2 j \int_{-\infty}^{\infty} Q_{v} e^{-\sigma D} \sinh (n g) d v \\
P_{v} & =-\frac{e^{-\sigma D}}{2 \sigma} \sum_{n=1}^{\infty} C_{n} \sinh (n g) \\
R_{v} & =\frac{e^{-\sigma D}}{2 \sigma} \sum_{m=1}^{\infty} E_{m} \cosh (m g)
\end{aligned}
$$

where: $\varepsilon_{\mathrm{m}}=2$ if $\mathrm{m}=0, \varepsilon_{\mathrm{m}}=1$ otherwise

$$
\mathrm{g}=\cosh ^{-1}(\sigma / \mathrm{W})
$$

\section{Field in the halfspace}

The normalized modal parameters satisfy the separation variable equations

for $\mathrm{X}>\mathrm{D}$.

$$
\tau^{2}=v^{2}+a^{2}\left(\beta^{2}-K_{3}^{2}\right)
$$

As $(\tau, v)$ are continuous variables in this region, the expressions for $\left(\mathrm{e}_{\mathrm{Z}}, \mathrm{h}_{\mathrm{Z}}\right)$ consist of superposition of continuum plane waves:

$$
\begin{aligned}
& e_{Z}=\int_{-\infty}^{\infty} G_{v} e^{-j Y v} e^{-\tau(X-D)} d v \\
& h_{Z}=\int_{-\infty}^{\infty} H_{v} e^{-j Y v} e^{-\tau(X-D)} d v
\end{aligned}
$$

where $\mathrm{G}_{v}$ and $\mathrm{H}_{v}$ are the $v$ functions to be determined.

The representations (10) of the fields are applicable to both polarizations. The transverse field components, in rectangular system, are given by hybrid formulation [1].

\section{Equivalent scattering parameters}

The set of coefficients $\left(P_{v}, Q_{v}, R_{v}, S_{v}, G_{v}, H_{v}\right)$ can be expressed by matching the fields tangential components on the planar interface. This leads to the equivalent scattering matrix.

$$
\left(\begin{array}{l}
Q_{v} \\
S_{v}
\end{array}\right)=\left[\begin{array}{cc}
S_{11}(v) & j S_{12}(v) \\
-j S_{21}(v) & S_{22}(v)
\end{array}\right]\left(\begin{array}{c}
P_{v} \\
R v
\end{array}\right)
$$

The term equivalent is used to emphasize that the fields are not power orthonormalized. The $\left(\mathrm{Q}_{v}, \mathrm{~S}_{\mathrm{v}}\right)$ and $\left(\mathrm{P}_{v}, \mathrm{R}_{v}\right)$ parameters are respectively the coefficients of the reflected and incident waves on the planar interface.

The generalized equivalent scattering matrix parameters are:

$$
\begin{aligned}
S_{11}(v)= & \frac{1}{\gamma}\left[\left(\sigma \mu_{r 2} Q_{3}^{2}-\tau \mu_{r 3} Q_{2}^{2}\right)\left(\sigma \eta_{2}^{2} Q_{3}^{2}+\tau \eta_{3}^{2} Q_{2}^{2}\right)+\alpha\right] \\
S_{12}(v) & =\frac{1}{\gamma}\left[2 \eta_{e f} \sqrt{\mu_{e f}} Y_{o} \sigma v\left(\eta_{2} Q_{3} V_{3}\right)^{2}\right] \\
S_{21}(v) & =\frac{1}{\gamma}\left[2 \eta_{e f} \sqrt{\mu_{e f}} Z_{o} \sigma v \mu_{r 2}\left(Q_{3} V_{3}\right)^{2}\right] \\
S_{22}(v)= & \frac{1}{\gamma}\left[\left(\sigma \eta_{2}^{2} Q_{3}^{2}-\tau \eta_{3}^{2} Q_{2}^{2}\right)\left(\sigma \mu_{r 2} Q_{3}^{2}+\tau \mu_{r 3} Q_{2}^{2}\right)+\alpha\right] \\
\text { where } \gamma & =\left[\left(\sigma \mu_{\mathrm{r} 2} \mathrm{Q}_{3}^{2}+\tau \mu_{\mathrm{r} 3} \mathrm{Q}_{2}^{2}\right)\left(\sigma \eta_{2}^{2} \mathrm{Q}_{3}^{2}+\tau \eta_{3}{ }^{2} \mathrm{Q}_{2}{ }^{2}\right)-\alpha\right] \\
\alpha & =\left(\eta_{\mathrm{ef}} \mathrm{V}_{3}^{2}\right)^{2} \mu_{\mathrm{ef}}\left(\eta_{\mathrm{ef}} \mu_{\mathrm{ef}}\right)^{1 / 2}=\beta / \mathrm{K}_{\mathrm{o}} \\
\mathrm{V}_{3} & =\mathrm{aK}_{\mathrm{o}}\left(\eta_{3}{ }^{2} \mu_{\mathrm{r} 3}-\eta_{2}{ }^{2} \mu_{\mathrm{r} 2}\right)^{1 / 2} \quad \mathrm{Z}_{\mathrm{o}}=120 \pi
\end{aligned}
$$

\section{DUALITY THEOREM APPLICATION}

Both polarization states of the fundamental mode are obtained by (12).

The equivalent scattering-matrix parameters related to polarization state-Y or TE, as described by (2) and (3), is obtained by doing: $\mu_{\mathrm{r} 1}=\mu_{\mathrm{r} 2}=\mu_{\mathrm{r} 3}=\mu_{\mathrm{ef}}=1$ in (12).

The other polarization state, the TM approach formulation or state-X, is obtained by applying the duality theorem in (12), and also by considering the new relative permeability values equal to one.

\section{EIGENVALUE EQUATIONS}

In this section, the general eigenvalue matrix of the polished-optical fiber with reduction of the index profile in the cladding is derived.

We express the cladding coefficients (3) in terms of the core coefficients (2). This is obtained by considering the continuity of the polar tangential components across the core/cladding interface, as follows: 


$$
\begin{gathered}
\left(\begin{array}{c}
C_{n} \\
D_{n} \\
E_{n} \\
F_{n}
\end{array}\right)=\frac{1}{\gamma_{n}}\left[\begin{array}{cc}
\left(J_{n} I_{n}^{\prime}+\alpha_{1} J_{n}^{\prime} I_{n}\right) & -\left(n \alpha_{2} J_{n} I_{n}\right) \\
-\left(J_{n} K_{n}^{\prime}+\alpha_{1} J_{n}^{\prime} K_{n}\right) & \left(n \alpha_{2} J_{n} K_{n}\right) \\
-\left(n \alpha_{3} J_{n} I_{n}\right) & \left(J_{n} I_{n}^{\prime}+\alpha_{4} J_{n}^{\prime} I_{n}\right) \\
\left(n \alpha_{3} J_{n} K_{n}\right) & -\left(J_{n} K_{n}^{\prime}+\alpha_{4} J_{n}^{\prime} K_{n}\right)
\end{array}\right]\left(\begin{array}{l}
A_{n} \\
B_{n}
\end{array}\right) \\
\alpha_{1}=\frac{W \eta_{1}^{2} \mu_{r 1}}{U \eta_{2}^{2} \mu_{r 2}} \quad \alpha_{2}=Z \frac{V_{o}^{2} \eta_{e f} \sqrt{\mu_{e f}}}{U^{2} W \eta_{2}^{2} \mu_{r 2}} \\
\alpha_{3}=Y_{o} \frac{V^{2} \eta_{e f} \sqrt{\mu_{e f}}}{U^{2} W} \quad \alpha_{4}=\frac{W}{U}
\end{gathered}
$$

The continuity of the tangential components across the interface-plane, in rectangular system, is expressed by:

$\mathrm{Q}_{\mathrm{v}}=-\mathrm{je}(\sigma) \Sigma \mathrm{C}_{\mathrm{m}} \sinh (\mathrm{mg}) \mathrm{S}_{11}(\mathrm{v})+\mathrm{je}(\sigma) \Sigma \mathrm{E}_{\mathrm{m}} \cosh (\mathrm{mg}) \mathrm{S}_{12}(\mathrm{v})$

$\mathrm{S}_{\mathrm{v}}=-\mathrm{e}(\sigma) \Sigma \mathrm{C}_{\mathrm{m}} \sinh (\mathrm{mg}) \mathrm{S}_{21}(\mathrm{v})+\mathrm{e}(\sigma) \Sigma \mathrm{E}_{\mathrm{m}} \cosh (\mathrm{mg}) \mathrm{S}_{22}(\mathrm{v})$

where: $\mathrm{S}_{\mathrm{jk}}(\mathrm{v}) \mathrm{I}, \mathrm{k}=1,2$ are given by (12)

$\mathrm{C}_{\mathrm{m}}, \mathrm{E}_{\mathrm{m}}$ are expressed by (13)

$\mathrm{g}=\cosh ^{-1}(\sigma / \mathrm{W})$, and

$$
\begin{gathered}
D_{m}=2 j \int_{-\infty}^{\infty} Q_{v} e^{-\sigma D} \operatorname{senh}(m g) d v \\
\varepsilon_{m} F_{m}=2 \int_{-\infty}^{\infty} S_{v} e^{-\sigma D} \cosh (m g) d v
\end{gathered}
$$

where:

$$
\mathrm{e}(\sigma)=\mathrm{e}^{-\sigma \mathrm{D}} / \sigma
$$

If (15) is multiplied to $\sinh (\mathrm{mg}),(16)$ is multiplied to $\cosh (\mathrm{mg})$ and both are integrated on $v$ variable, then, the respective terms of the resulting equations are substituted by (13) and (17).

The final results corresponding to the general eigenvalue matrix in terms of the core expansion coefficients is as follows:

$$
\left(\begin{array}{ll}
{\left[M^{11}\right]} & {\left[M^{12}\right]} \\
{\left[M^{21}\right]} & {\left[M^{22}\right]}
\end{array}\right)\left(\begin{array}{l}
{[A]} \\
{[B]}
\end{array}\right)=0
$$

where: $\left[\mathrm{M}^{1 \mathrm{~K}}\right]$ are the matrix defined by $\mathrm{n}=0,1,2,3$

$$
\begin{aligned}
& \mathrm{M}_{\mathrm{nm}}{ }^{11}=\varepsilon_{\mathrm{n}}\left(\mathrm{J}_{\mathrm{n}} \mathrm{K}_{\mathrm{n}}{ }^{\prime}+\alpha_{4} \mathrm{~J}_{\mathrm{n}}{ }^{\prime} \mathrm{K}_{\mathrm{n}}\right)+\sum_{\infty}^{\infty}\left(\mathrm{TA}_{\mathrm{m}} \mathrm{S}_{\mathrm{nm}}{ }^{11}+\mathrm{TB}_{\mathrm{m}} \mathrm{S}_{\mathrm{nm}}{ }^{12}\right) \\
& \mathrm{M}_{\mathrm{nm}}{ }^{21}=\left(\mathrm{n} \alpha_{2} \mathrm{~J}_{\mathrm{n}} \mathrm{K}_{\mathrm{n}}\right) \delta_{\mathrm{nm}}+\sum_{\mathrm{m}=0}^{\infty}\left(\mathrm{TA}_{\mathrm{m}} \mathrm{S}_{\mathrm{nm}}{ }^{21}+\mathrm{TB}_{\mathrm{m}} \mathrm{S}_{\mathrm{nm}}{ }^{22}\right) \\
& \mathrm{n}=1,2,3,4 \\
& \mathrm{M}_{\mathrm{nm}}{ }^{21}=\left(\mathrm{n} \alpha_{3} \mathrm{~J}_{\mathrm{n}} \mathrm{K}_{\mathrm{n}}\right) \delta_{\mathrm{nm}}+\sum_{\mathrm{m}=1}^{\infty}\left(\mathrm{TC}_{\mathrm{m}} \mathrm{S}_{\mathrm{nm}}{ }^{12}+\mathrm{TD}_{\mathrm{m}} \mathrm{S}_{\mathrm{nm}}{ }^{11}\right) \\
& \mathrm{M}_{\mathrm{nm}}{ }^{22}=\varepsilon_{\mathrm{n}}\left(\mathrm{J}_{\mathrm{n}} \mathrm{K}_{\mathrm{n}}{ }^{\prime}+\alpha_{4} \mathrm{~J}_{\mathrm{n}}{ }^{\prime} \mathrm{K}_{\mathrm{n}}\right)+\sum_{\mathrm{m}=0}\left(\mathrm{TC}_{\mathrm{m}} \mathrm{S}_{\mathrm{nm}}{ }^{22}+\mathrm{TD}_{\mathrm{m}} \mathrm{S}_{\mathrm{nm}}{ }^{21}\right) \\
& \mathrm{TA}_{\mathrm{m}}=\mathrm{J}_{\mathrm{m}} \mathrm{I}_{\mathrm{m}}{ }^{\prime}+\alpha_{4} \mathrm{~J}_{\mathrm{m}}{ }^{\prime} \mathrm{I}_{\mathrm{m}} \quad \mathrm{TB}_{\mathrm{m}}=\mathrm{m} \alpha_{2} \mathrm{~J}_{\mathrm{m}} \mathrm{I}_{\mathrm{m}} \\
& \mathrm{TC}_{\mathrm{m}}=\mathrm{J}_{\mathrm{m}} \mathrm{I}_{\mathrm{m}}+\alpha_{1} \mathrm{~J}_{\mathrm{m}} \mathrm{I}_{\mathrm{m}} \quad \mathrm{TD}_{\mathrm{m}}=\mathrm{m} \alpha_{3} \mathrm{~J}_{\mathrm{m}} \mathrm{I}_{\mathrm{m}}
\end{aligned}
$$

$\delta_{\mathrm{nm}}$ is the Kronecker delta function

$[\mathrm{A}]$ and $[\mathrm{B}]$ are infinite column vectors

$\alpha_{\mathrm{k}} ; \mathrm{k}=1,2,3,4$ is given by (14).

The polarization state-Y eigenvalue matrix, also called the equivalent TE-mode (h-mode) eingenvalue matrix, is obtained by doing the permeability values equal to one in (12) - (14) and (19).

The polarization state- $X$ eigenvalue matrix, also known by equivalent TM-mode (e-mode) is obtained by applying the duality theorem in (12) - (14) and (19) and by considering the new permeability values equal to one.

The scattering parameters of the both polarization states are:

$\mathrm{S}^{11}{ }_{n \mathrm{~m}}(\mathrm{~h})=\int \mathrm{S}^{\mathrm{h}}{ }_{11}(\mathrm{v}) \cosh (\mathrm{ng}) \cosh (\mathrm{mg}) \mathrm{e}(\sigma) \mathrm{d} v$ $\mathrm{S}^{22}{ }_{n m}(\mathrm{e})=\int \mathrm{S}_{11}{ }_{11}(v) \sinh (\mathrm{ng}) \sinh (\mathrm{mg}) \mathrm{e}(\sigma) \mathrm{d} v$ $\mathrm{S}^{12}{ }_{\mathrm{nm}}(\mathrm{h})=\int \mathrm{S}^{\mathrm{h}}{ }_{12}(\mathrm{v}) \sinh (\mathrm{ng}) \cosh (\mathrm{mg}) \mathrm{e}(\sigma) \mathrm{d} v$ $\mathrm{S}^{21}{ }_{n m}(\mathrm{e})=\int \mathrm{S}_{12}{ }_{12}(v) \sinh (\mathrm{ng}) \cosh (\mathrm{mg}) \mathrm{e}(\sigma) \mathrm{d} v$ $\mathrm{S}^{22}{ }_{\mathrm{nm}}(\mathrm{h})=\int \mathrm{S}^{\mathrm{h}}{ }_{22}(\mathrm{v}) \sinh (\mathrm{ng}) \sinh (\mathrm{mg}) \mathrm{e}(\sigma) \mathrm{d} v$ $\mathrm{S}^{11}{ }_{\mathrm{nm}}(\mathrm{e})=\int \mathrm{S}^{\mathrm{h}}{ }_{22}(\mathrm{v}) \cosh (\mathrm{ng}) \cosh (\mathrm{mg}) \mathrm{e}(\sigma) \mathrm{d} v$

where e $(\sigma)$ is given by (18) and the integration limits are $(-\infty, \infty)$.

\section{RESULTS}

In this section, various results obtained from the theory developed here are presented.

The integration of the set of equations in (20) is done on g-plane. Therefore the following transformations are used:

$$
\cosh (g)=\sigma / W, \sinh (g)=v / W, d v=W \cosh (g) d g
$$

The numerical calculations were performed by using standard library subroutines of Visual Fortran 77 for Bessel functions, matrices and determinants. 
The waveguide geometry of the analysed polishedoptical fiber is shown in figure 1 . The cross-section shows the radius "a" of the circular core and "d" is the halfspace distance from the core. $\eta_{1}=1.447, \eta_{2}=$ $1, \eta_{3}=1.4, \lambda=1.3 \mu \mathrm{m}, \mathrm{a}=4.95 \mu \mathrm{m}$.

Figure 2 shows the $\eta_{\text {ef }}$ variation versus normalized frequency "V". In figure 3 we can see a slice of this result in detail. It can also be seen the birefringence characteristic of the two polarization states.

Figure 4 shows the core transversal phase parameter "U" variation versus normalized frequency. In figure 5 a slice of the figure 4 is presented in detail.

The two normalized modal parameters " $U$ " of the respective orthogonal polarizations are plotted in figure 6 for $\mathrm{V}=23$ in terms of the core / halfspace normalized separation " $D$ ". We verify that the birefringence becomes apparent only for " $D$ " very close to core contact $(D=1)$. The solid lines correspond to the polarization state- $X$ and the dashed line to the polarization state-Y.

The $U$ values in figure 6 have been compared with those calculated by [2]. Agreement is found to be better than $3 \%$.

$\eta_{\mathrm{ef}}$

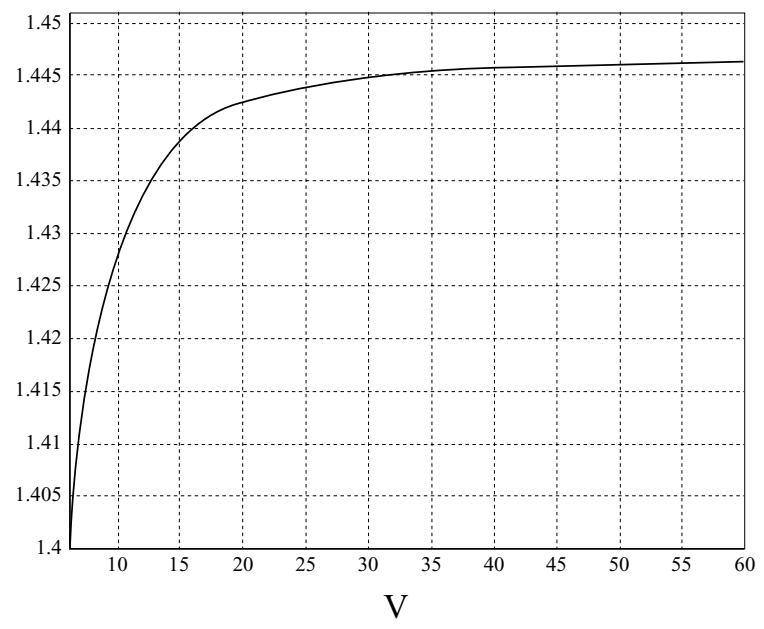

Figure 2. The effective-index variation versus normalized frequency $\mathrm{V}$.
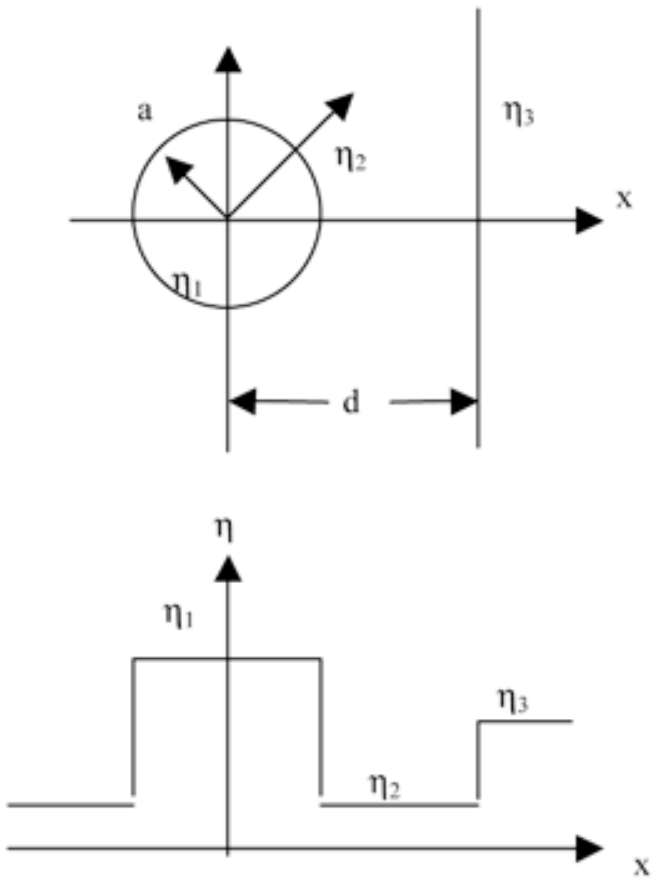

Figure 1. Waveguide geometry.

The cross-section shows the radius "a" of the circular core and "d" is the halfspace distance from the core.

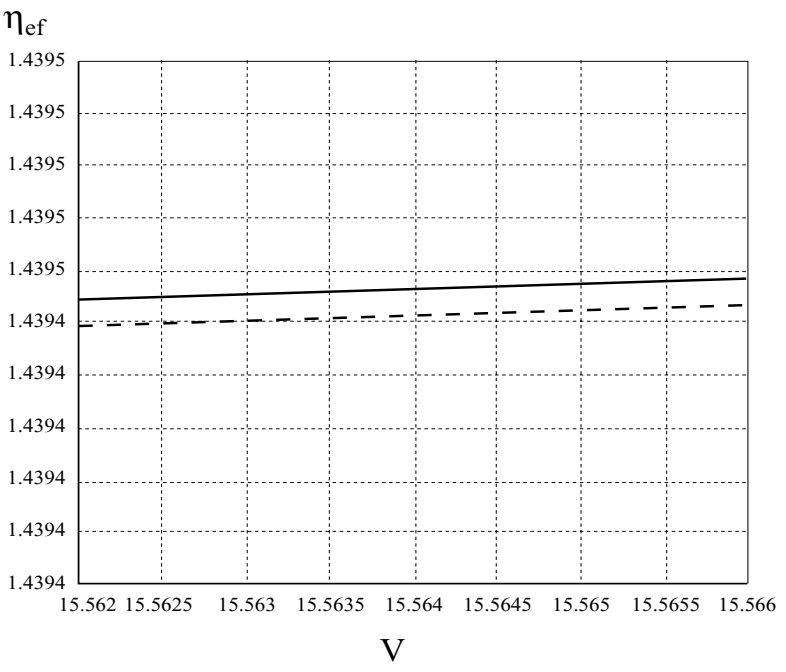

Figure 3. A graphic slice of the effective-index variation versus normalized frequency $\mathrm{V}$. 
$\mathrm{U}$

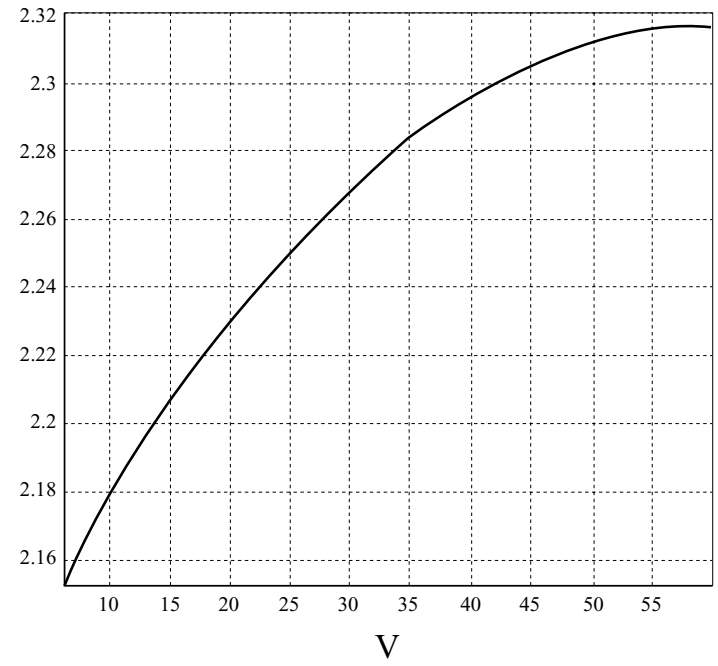

Figure 4. The core transversal phase parameter U variation versus normalized frequency.
$\mathrm{U}$

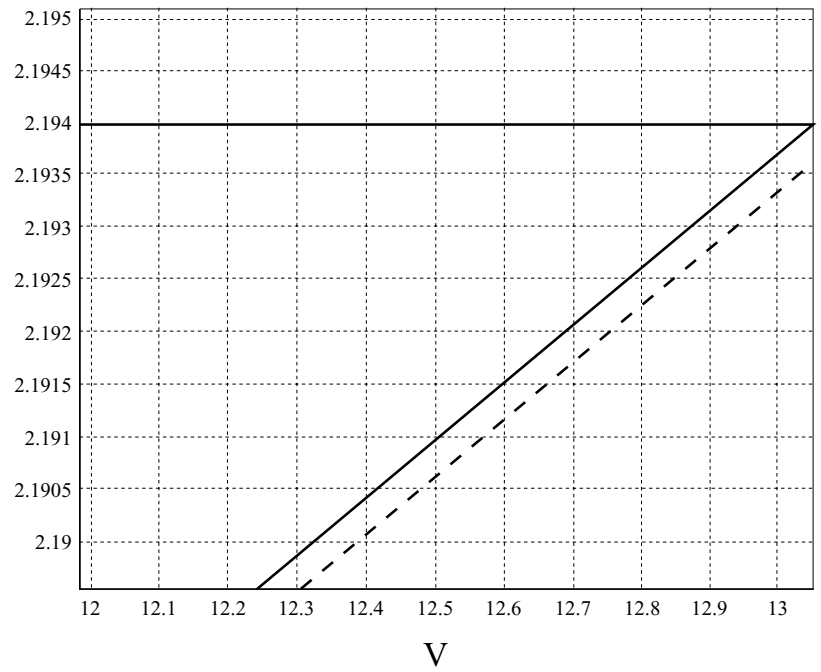

Figure 5. A graphic slice of the core transversal phase parameter $U$ variation versus normalized frequency $\mathrm{V}$.

$\mathrm{U}$

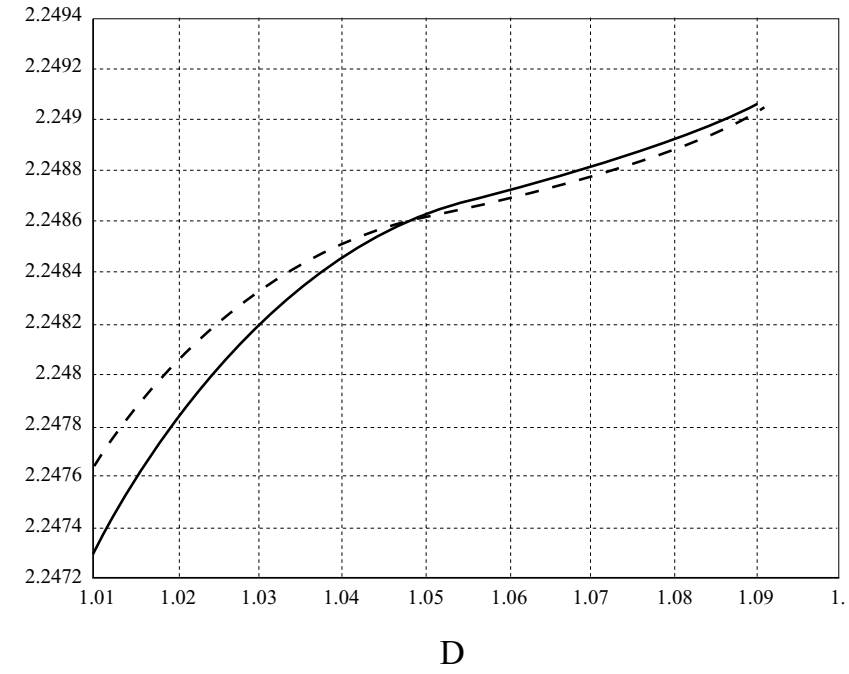

Figure 6. The two normalized modal parameters $\mathrm{U}$ of the respective orthogonal polarizations, for $\mathrm{V}=23$, in terms of the normalized distance D. The solid lines correspond to the polarization state-X and the dashed line to the polarization state-Y.

\section{CONCLUSION}

In this paper a new approach to model the polished fiber waveguide is developed. This model corresponds to only one set of equations which both polarization states of the fundamental mode can be analyzed.

The results were compared to [2] and an error smaller than $3 \%$ was obtained. Further verification with classical numerical methods will be done in the near future.
The D-shaped optical fiber is an optical element whose analysis still offers a lot of practical results to be obtained. Nowadays, the D-shaped fiber is considered the essential component in several optical devices. Its most common applications are as components of sensors, filters, antennas and even in chemical devices [4-12]. So, the studies about D-shaped fibers are very promissory enterprises that promise to reveal several useful applications. 


\section{ACKNOWLEDGMENT}

The authors are very grateful to Prof. Jose Ricardo Bergmann (CETUC/PUC/Rio de Janeiro) for his invaluable cooperation.

\section{REFERENCES}

[1] A.W. Snyder and J.D. Love. "Optical Waveguide Theory”. Chapman and Hall. London. 1988.

[2] D. Marcuse, J.D. Love and F. Ladoucer. "Vector modes of D-shaped fibers". IEE-Proceeding-J. Vol. 139. No 2, pp. 117-126. April 1992.

[3] C. Vassalo. "Rigorous theory for modes of optical fibers with cladding limited by a plane". Electron Lett, $\mathrm{N}^{\circ}$ 22, pp. 944-945. 1986.

[4] H.S. Al-Raweshidy, F.A. Muhammad, J.M. Senior, "Compensation for surface contamination with D-fiber sensor (Elsevier)". Sensor and Actuators B-40, pp. 59-63. 1997.

[5] H.S. Al-Raweshidy, A.Bhatti, G. Murttaza. "Radio-over-fibre using D-fiber antenna". Optical \& Laser Technology. No 33, pp. 145-151. 2001.

[6] H.S. Al-Raweshidy, A.Bhatti, G. Murttaza. "Dfiber Antenna for Radio-over-fibre in Mobile Communication Systems". IEEE-VTC' 99, pp. 2795-2799. 1999.
[7] F.A. Muhammad, G. Stewart. "Polarised finitediference analysis of D-fiber and application for chemical sensing". International Journal of Optoelectronics. Vol. 7. Nº 6, pp. 705-721. 1992.

[8] Siao-Min Tseng, Ssu-Pin Ma. "High-Performance Side-Polished Fibers and Applications as Liquid Crystal Clad Fiber Polarized". Journal of Light Wave Technology. Vol. 15, pp. 1554-1559. August 1997.

[9] Shiao-Min Tseng, Chin-Lin Chen. "Side-polished fibers". Applied Optics. Vol. 31. No 18, pp. 3447. June 1992.

[10] W. Johnstone, K. MacCallion, G. Fawcett. "Tunable in-line fiber-optic bandpass filter". Optics Letter. Vol. 19. No 8, pp. 542-544. April 1994.

[11] W. Johnstone, G. Thursby, K. MacCallion, D. Moodie. "Fiber-optic refractometer that utilizes multimode waveguide overlay devices". Optics Letters. Vol. 17. $\mathrm{N}^{\mathrm{o}}$ 21, pp. 1538-1540. November 1992.

[12] W. Johnstone, G. Thursby, S. Murray, M. Gill, A. MacDnach, D. Moodie, B. Culshaw. "Fiber Optic Modulators using Active Multimode Waveguide Overlays". Electronics Letters. 23 rd. Vol. 27. $\mathrm{N}^{\circ}$ 11, pp. 894-896. May 1991. 